\title{
A case of congenital lobar emphysema
}

\author{
M T Abiodun ${ }^{1}$, W Osarogiagbon ${ }^{2}$, O Oviawe $^{3}$ \\ Sri Lanka Journal of Child Health, 2012; 41(3): 146-147
}

(Keywords: congenital lobar emphysema; infant; dyspnoea)

\section{Case report}

A two month old boy was admitted to the paediatric ward of the University of Benin Teaching Hospital, Nigeria with tachypnoea and poor suckling from the $4^{\text {th }}$ hour of life and fever, cough and dyspnoea of two weeks duration. There was no grunting. He was delivered at term via spontaneous vertex delivery in a rural secondary health facility where mother received routine antenatal care. No obstetric ultrasound scan was done. Immediate post partum period was normal. Birth weight was $3.1 \mathrm{~kg}$ but he gained only $0.7 \mathrm{~kg}$ over the next 2 months despite exclusive breastfeeding because respiratory distress interfered with suckling. $\mathrm{He}$ has received BCG, OPV1\&2 and DPT1. Both parents are petty traders with secondary level of education.

Physical examination revealed marked respiratory distress. Respiratory rate was 86 cycles per minute, pulse rate was 140 beats per minute and temperature was $38.7^{\circ} \mathrm{C}$. There was normal facies and no cyanosis. His weight was $3.8 \mathrm{~kg}$ ( $71 \%$ of expected), length was $56 \mathrm{~cm}$ and head circumference $38 \mathrm{~cm}$, both normal for age.

Respiratory system examination revealed mild bulging of the left hemithorax. Trachea was deviated to the right, percussion note was hyper-resonant and breath sounds were reduced in the left hemithorax. Apex beat was displaced medially to the left parasternal edge, at $4^{\text {th }}$ intercostal space. Other systems were essentially normal.

${ }^{1}$ Senior Registrar, ${ }^{2}$ Consultant Paediatrician,
Department of Child Health, ${ }^{3}$ Professor of Child
Health and Director of Institute of Child Health,
University of Benin Teaching Hospital, Benin city,
Edo state, Nigeria

(Received on 1 August 2011: Accepted after revision on 9 September 2011)
The initial diagnosis was bronchopneumonia complicated with a left-sided pneumothorax. Urgent chest radiograph (Figure 1a) showed hyperlucent, hyperinflated left upper lobe with reduced lung markings and collapse of the left lower lobe. There was herniation of the left upper lobe into the mediastinum causing a mediastinal shift to the right. Echocardiography showed no structural anomaly. A planned computerized tomography (CT) scan of the chest was unachieved due to financial constraints. Final diagnosis was congenital lobar emphysema (CLE). He received intravenous antibiotics, supplemental oxygen and other supportive care. He has improved on conservative management and the superimposed acute respiratory infection has resolved. He was planned for a lobectomy. Meanwhile, he is being followed up at the paediatric out-patient department.

\section{Discussion}

Congenital lobar emphysema (CLE) is a rare lung malformation that may cause persistent respiratory distress in infants. It is due to hyperinflation of a lung lobe, collapse of adjacent lobe, compression of contralateral normal lung and mediastinal shift ${ }^{1}$. It has a prevalence of 1 in 20,000 to 1 in 30,000 live births and is three times commoner in males ${ }^{2}$. The underlying defect in CLE is often deficiency of bronchial cartilage and airway collapse creating a 'ball-valve' mechanism and air trapping during expiration ${ }^{1}$. However, a definitive causative agent may not be identified in about 50 percent of cases ${ }^{2}$. The left upper lobe is most commonly affected but any lobe can be involved and rarely it is bilateral ${ }^{1,2}$. About a half of cases are symptomatic in the neonatal period and nearly all by six months of age ${ }^{2,3}$. They often present with tachypnoea and dyspnoea but recurrent pneumonia and failure to thrive may complicate the illness ${ }^{2}$. Factors that may enhance the recurrence of severe symptoms in CLE include superimposed respiratory tract infections and coexistence of congenital heart disease ${ }^{1,3}$. 

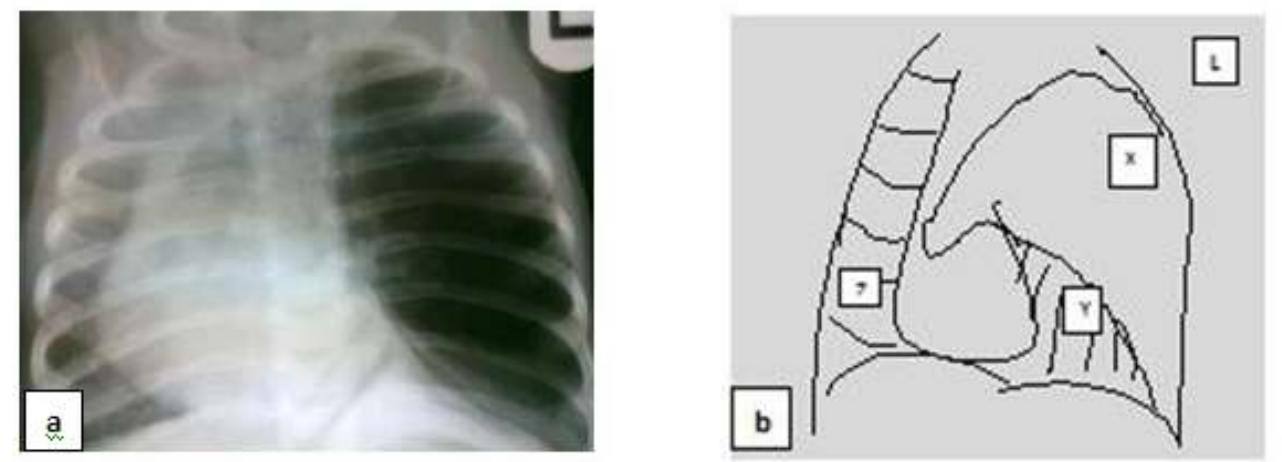

Figure la: Chest radiograph (PA view) showing marked hyperinflation of the left upper lobe herniating into the mediastinum, collapse of the left lower lobe and mediastinal shift to the right. $1 b$ : A sketch of the patient's chest radiograph highlighting the hyper-inflated left upper lobe [X], collapsed left lower lobe [Y], compressed right lung [Z], depressed left hemi-diaphragm and displaced heart.

Our patient presented in early infancy with typical features of CLE dating from the early neonatal period. He had progressive respiratory distress that interfered with suckling and led to poor weight gain. Khemiri et $\mathrm{al}^{3}$ reported progressive respiratory distress in $65 \%$ of 17 patients. Chest $\mathrm{X}$ ray (CXR) and $\mathrm{CT}$ scans showed hyper-aeration of the affected lobes in all cases ${ }^{3}$. Thakral et al reported similar features $^{2}$. We confirmed the diagnosis of CLE in our patient based on the typical clinical and CXR features including the hyper-inflated left upper lobe with cardio-mediastinal shift to the right, creating retrosternal lucency (Figures 1a and 1b). The bulging of the left hemithorax noted in this case is rarely reported ${ }^{2,3}$. This clinical finding is due to the severity of the disease in our patient.

Prenatal diagnosis of CLE can be made with ultrasonography showing hyperechogenicity but in utero surgical management is not recommended ${ }^{4}$. Definitive diagnosis of CLE can be made postnatally from typical CXR findings as in this infant ${ }^{3,5}$. CT of the thorax can delineate the anatomy of the affected lobe by showing stretched, attenuated, spread-out vessels in the emphysematous lobe and compressive atelectasis of other lobes 5 . Differential diagnosis of CLE includes pneumothorax but presence of linear bronchovascular and alveolar markings in CLE differentiates it from pneumothorax which has no lung makings ${ }^{5,6}$.

Conservative management is suitable for mild cases ${ }^{7}$ but severely symptomatic cases like ours will benefit from surgical excision of the affected $\operatorname{lobe}^{5,7}$. Delayed treatment can result in failure to thrive, atelectasis and pulmonary air leak ${ }^{2}$. However, surgical resection was deferred in this case because the parents could not afford it at present.

\section{References}

1. Kravitz RM. Congenital malformations of the lung. Pediatric Clinics of North America 1994; 41:453-72.

2. Thakral CL, Maji DC, Sajwani MJ. Congenital lobar emphysema: experience with 21 cases. Pediatric Surgery International 2001; 17:88-91. http://dx.doi.org/10.1007/s003830000506

3. Khemiri M, Khaldi F, Ben Becher S, Chaouachi B, Houissa $\mathrm{T}$, et al. Congenital lobar emphysema: Report of 17 cases. La Tunisie Medicale 2008; 86(4):373-7.

4. Babu R, Kyle P, Spicer RD. Prenatal sonographic features of congenital lobar emphysema. Fetal Diagnosis and Therapy 2001; 16:200-2. http://dx.doi.org/10.1159/000053909

5. Ulku R, Onat S, Ozçelik C. Congenital lobar emphysema: differential diagnosis and therapeutic approach. Pediatrics International 2008; 50(5):658-61. http://dx.doi.org/10.1111/j.1442200X.2008.02630.x

6. Powers JE, Counselman FL. Congenital lobar emphysema: tube thoracostomy not the treatment. Pediatric Emergency Care 2005; 21:760-2. http://dx.doi.org/10.1097/01.pec.0000186432.8208 $\underline{5 . b f}$

7. Ceran S, Altuntas B, Sunam GS, Bulut I. Congenital lobar emphysema: Is surgery routinely necessary? African Journal of Paediatric Surgery 2010; 7:36-7.

http://dx.doi.org/10.4103/0189-6725.59360 